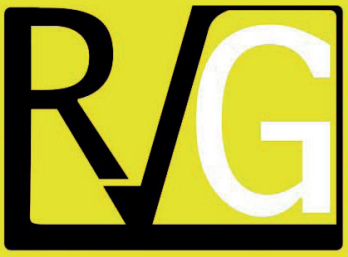

Julio - Septiembre, 2021

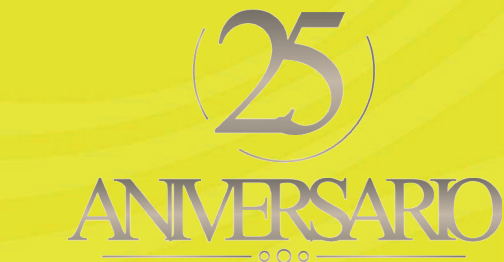

ANMERSARO
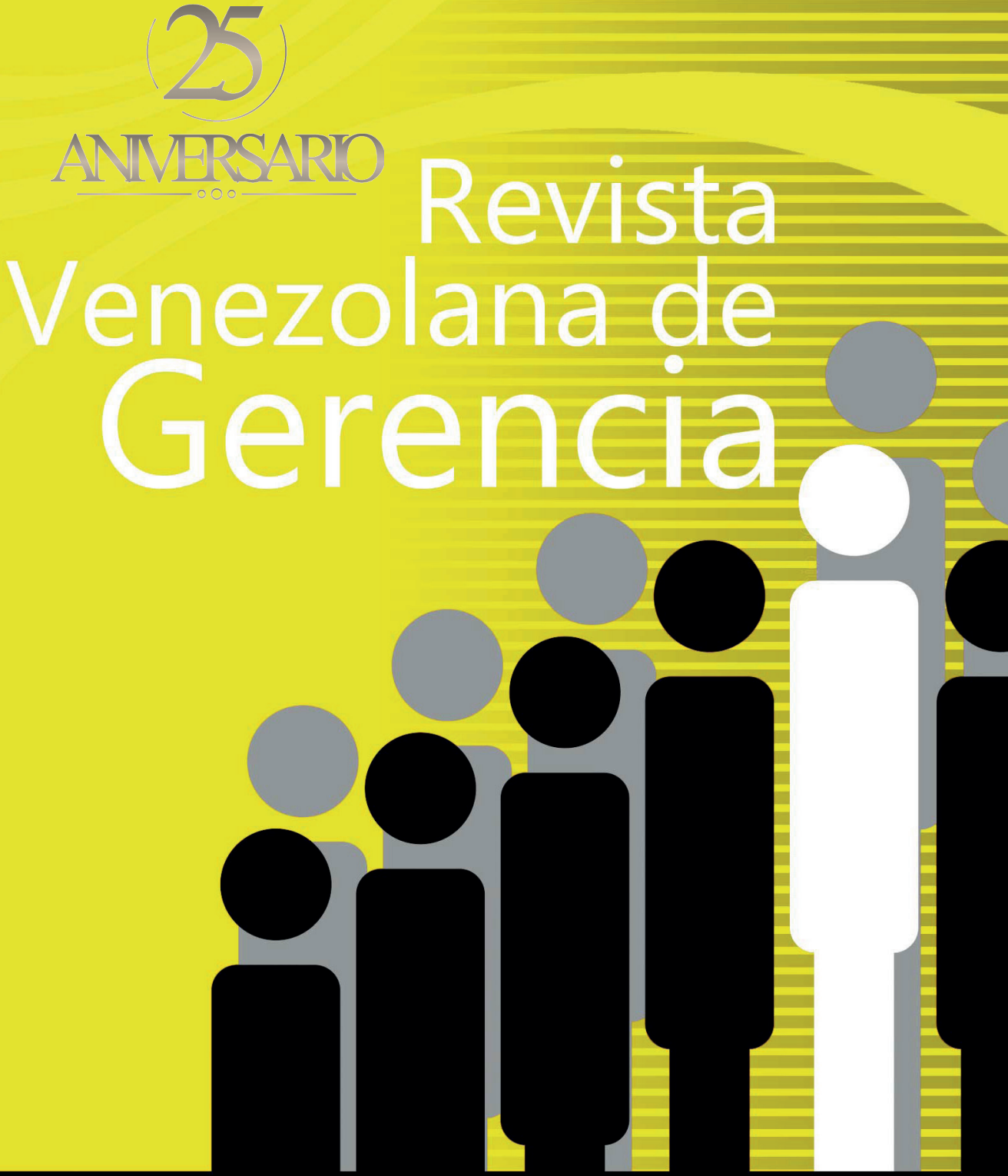

UNIVERSIDAD DEL ZULIA (LUZ)

Facultad de Ciencias Económicas y Sociales Centro de Estudios de la Empresa

ISSN 1315-99

Esta obra está bajo una licencia de Creative Comm Reconocimiento-NoComercial-Compartirlgual 3.0 Unpo http://creativecommons.org/licenses/by-nc-sa/3.0/deed.es 
COMO CITAR: Urdaneta Montiel, A. J., Borgucci Garcia, E. V., González Ordóñez, A. I., y Luciani Toro, L. R. (2021). Función empresarial y concentración de pequeñas y medianas empresas en la Provincia de El Oro - Ecuador. Revista Venezolana de Gerencia, 26(95), 776-801. https:// doi.org/10.52080/rvgluz.27.95.21
Universidad del Zulia (LUZ)

Revista Venezolana de Gerencia (RVG)

Año 26 No. 95 Julio-Septiembre 2021, 776-801

ISSN 1315-9984 / e-ISSN 2477-9423

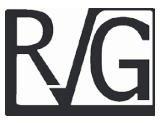

\title{
Función empresarial y concentración de pequeñas y medianas empresas en la Provincia de El Oro - Ecuador
}

\author{
Urdaneta Montiel, Armando José* \\ Borgucci Garcia, Emmanuel Vitorio** \\ González Ordóñez, Andreina Inés*** \\ Luciani Toro, Laura Rosa****
}

\section{Resumen}

Las pymes contribuyen con el crecimiento económico por su potencial para generar empleo y valor agregado. Este estudio analizó la concentración de las pymes por sectores económicos en la Provincia de El Oro, Ecuador, y cómo esto afectó su tasa de crecimiento económico. Metodológicamente, La investigación es de tipo descriptiva y correlacional, se utilizaron datos del Instituto Nacional de Estadística y Censos y del Banco Central de Ecuador entre 2006 y 2017. Los principales hallazgos fueron: 1) $28 \%$

Aceptado: 12-03-21

* Postdoctorado en Integración y Desarrollo de América Latina. Doctor en Ciencias Económicas. Doctor en Ciencias Gerenciales. Magister en Telemática. Magister en Gerencia Empresarial. Ingeniero en Computación. Profesor Titular Agregado I, de la Universidad Metropolitana del Ecuador. Docente Titular invitado en Universidad del Zulia. Zulia, Venezuela. E-mail: aurdaneta@umet.edu.ec ORCID: https://orcid. org/0000-0002-9825-9453

** Postdoctorado en Ciencias Económicas. Postdoctorado en Gerencia y Políticas Públicas. Doctor en Ciencias Sociales. Maestría en Banca y Finanzas. Maestría en Economía, mención Macroeconomía y Política Económica. Maestría en Gerencia de Empresas. Profesor de la Universidad del Zulia (LUZ), Maracaibo, Venezuela. Jefe del Departamento de Macroeconomía de la Escuela de Economía y Director del Instituto de Investigaciones de FCES-LUZ. Zulia, Venezuela. E-mail: emmanuelborgucci@gmail.com

*** Universidad Metropolitana del Ecuador, sede Machala. Doctora en Planificación y Gestión del Desarrollo Regional (Universidad del Zulia, Venezuela). Magister Scientiarum en Evaluación de Impacto en Salud y Ambiente (Cendes, UCV, Venezuela). Ingeniero Agrónomo (UNEFM, Venezuela). Docente titular Agregado 2. E-mail: aigonzalez@umet.edu.ec ORCID: https://orcid.org/0000-0003-2209-2295

**** Universidad Metropolitana del Ecuador Sede Machala Universidad Metropolitana del Ecuador, sede Machala. Doctora en Gerencia (Universidad Yacambú); Magister en Ciencias Contables (Universidad de Los Andes ULA), Lic. en Contaduría Pública (Universidad de Los Andes - ULA), Coordinadora Académica Universidad Metropolitana del Ecuador Sede Machala - Línea de investigación: Emprendimiento, productividad y competitividad en organizaciones empresariales y de la administración pública. Profesora Titular Agregado I. Categoría SENESCYT REG-INV-17-02036. Dirección: Machala Ecuador- 070150 - Teléfono: +593982665863. E-mail: lauraluciani62@gmail.com ORCID: https://orcid.org/0000-0001-9061-3203 
de las PYMES se encuentran en el sector comercio, mientras el $53 \%$ en servicios; 2) No obstante, el comercio representa $49 \%$ del mercado y los servicios $12 \%$. De lo antes expuesto, $81 \%$ de las PYMES pertenecen al sector terciario de la economía. En consecuencia, la región debe ampliar su base económica mediante: a) la atracción de capital en el sector transformador; 2) que el desarrollo de la manufactura comience con el sector agroindustrial; 3) por tener puerto, atraer industrias del interior del país o que ofrezca mejores incentivos que los puertos competidores. En consecuencia, la región debe orientar su función empresarial hacia el desarrollo de la manufactura sin detrimento de otros sectores que se han consolidado en la provincia de El Oro.

Palabras clave: PYMES; función empresarial; actividad económica; ingreso

\title{
Business Function And Concentration Of Smes In The Province Of El Oro - Ecuador
}

\begin{abstract}
SMEs contribute to the country's economic growth because of their potential to generate employment and gross value added. This study analyzed the concentration of SMEs by economic sectors in the province of El Oro, Ecuador, and how this affected their economic growth rate. Methodologically, the research is descriptive and correlational, the data is from the National Institute of Statistics and Census and the Central Bank of Ecuador in the period 2006-2017. The main findings were: 1) $28 \%$ of SMEs are in the commerce sector, while $53 \%$ are in services; 2) However, commerce represents $49 \%$ of the market and services $12 \%$. From the above, $81 \%$ of SMEs belong to the tertiary sector of the economy. Consequently, the region must broaden its economic base by: a) attracting capital in the transforming sector; 2) the development of manufacturing begins with the agro-industrial sector; 3 ) having a port, it will attract industries from the interior of the country or that offer better incentives than competing ports. Consequently, the region should orient its business function towards the development of manufacturing without detriment to other sectors that have been consolidated in the province of El Oro.
\end{abstract}

Keywords: SMEs; business; function; economic activity; income

\section{Introducción}

La función empresarial depende de la productividad de los factores (Turgot, 1998¹); Cantillon, (2002[1959]); Schumpeter (1994[1954]) y (1976[1912]), Edgeworth, (2000[1881], o Cobb y Douglas (1928) entre

1 Turgot tiene el mérito de hacer una reformulación de la "ley" de los rendimientos. En su propuesta, Turgot expone que los rendimientos decrecientes tienen un intervalo según el cual hay rendimientos crecientes. Es decir, los rendimientos decrecientes no ocurren en toda la extensión de la aplicación de insumos o factores productivos y mucho menos desde el principio. Los rendimientos comienzan a decrecer desde el momento en que se ha alcanzado cierto punto. Esto es lo que se conoce como un caso especial de la "ley" de las proporciones variables. 
Función empresarial y la concentración de las pymes en la Provincia de el Oro, Ecuador

otros $^{2}$, la oportunidad de realizar nuevas inversiones y asociación para producir incrementos en la producción, maximizando el nivel de valor agregado, con rendimientos a escala crecientes, gracias al conocimiento, la división del trabajo, la especialización de la producción y la capacidad de innovación de la acción humana.

La concentración de pequeñas y medianas empresas en un solo sector 0 algunos sectores de la economía, produce que cada unidad de producción tenga una menor participación en el mercado y que la contribución empresarial al desarrollo económico sea muy limitada. Caso similar se observa en la provincia de El Oro, Ecuador, donde existe una alta concentración de las pequeñas y medianas empresas (PYMES) en los sectores comercio y servicios que producen una división del mercado en lugar de expansión. En consecuencia, hay una utilización de los factores de producción en actividades productivas cuyo costo de oportunidad de invertir en otros sectores económicos, es mayor al beneficio obtenido actualmente.

En el Ecuador, según datos del Instituto Nacional de Estadística y Censos (INEC) (2013) el total de microempresas es de $731.761(90,40 \%)$, pequeñas empresas $61.798(7,60 \%)$, medianas empresas $13.130(1,50 \%)$ y grandes empresas $3.883(0.5 \%)$, resultando un total de 810.272 empresas (Arguello, 2018). Asimismo, la clasificación de las empresas por actividad económica según el INEC de empresas se ubica en el sector servicios $(39,40 \%)$, seguido por el sector comercio $(37,10 \%)$, por el sector de agricultura y ganadería $(11,60 \%)$, el sector transporte y almacenamiento $(9,30 \%)$, las manufacturas $(7,90 \%)$ y el sector de alojamiento y comidas $(7,50 \%)$ (Arguello, 2018).

Es necesario desconcentrar la actividad empresarial de las PYMES desde el sector comercio y servicios, y dirigirlas hacia el resto de los sectores económicos, donde existen mayores posibilidades de generar un incremento en el nivel de valor agregado, como es el caso de la agricultura, manufactura y minería, y en los cuales los beneficios obtenidos respecto a la asignación de factores productivos son más rentables, sobre todo en materia de exportaciones, producción de bienes de consumo intermedio y finales.

Esto sin lugar a dudas crearía nuevas fuentes empleo, requería mayores inversiones de capital, demandaría nuevas tecnologías de información y comunicación para la automatización de los procesos de

2 Para Marshall (1963[1890]), se sabe, desde tiempos de Platón, que la eficiencia en el trabajo se incrementa notablemente cuando la producción se desarrolla dentro de una organización. Para Marshall, la organización más capacitada es aquella que usa más los recursos del entorno y obviamente la que más se beneficia a los que los rodea; pero en ocasiones no es así. Puede suceder que la lucha por la supervivencia no genera las mejores empresas y que la demanda de una empresa no siempre hace surgir la oferta de otra de manera automática. Sin embargo, Según Marshall, lo que él denominó como doctrina de la organización natural pecaba de exagerada acerca de las bondades de la división del trabajo. Para Marshall, esta doctrina no consideró las condiciones bajo las cuales las facultades pueden ser mejor desarrolladas: "Las facultades religiosas, morales, intelectuales y artísticas de que depende el progreso de la industria no se adquieren solo por lo que ellas pueden conseguirse, sino que se desarrollan por el placer y la felicidad que proporcionan; y del mismo modo, la organización de un Estado bien ordenado, ese gran factor de la prosperidad económica, es el producto de una infinita variedad de móviles, mucho de los cuales no tienen relación directa alguna con la riqueza nacional" (Marshall, 1963[1890]: 207-208). 
trabajo, dinamizaría las capacidades de reinversión, afectando positivamente los flujos de caja proyectado de las empresas, incrementando con ello sus márgenes de rentabilidad y niveles de productividad del negocio, generándose con un proceso de acumulación de capital, físico, humano, intelectual entre otros, que a la postre decantaría en un crecimiento económico diversificado y sostenido de todos los sectores productivos.

En el Ecuador las PYMES representan una fuente de empleo importante, por ello es necesario en el caso de la provincia de El Oro, no solo capacitarlas y adiestrarlas en materia económica-financiera sino también técnica, mediante políticas de estado que surjan de la triada sector productivo, academia y gobierno para integrar a las PYMES a otras sectores de la vida productiva nacional, donde se requiere mayor competitividad, se pueden obtener mejores beneficios y aumentar la cadena de valor de dicho sector, sin embargo es necesario conocer el panorama actual de los diferentes sectores económicos de la provincia como elemento fundamental para la instrumentación de políticas sectoriales por parte del estado.

Estas políticas sectoriales sin duda alguna disminuirían de forma ostensible la alta mortalidad de empresa, porque les abre un abanico de posibilidades al insertarlas en nuevos mercados, generando nuevas oportunidades de negocios y emprendimientos para elevar los niveles de competitividad en aquellos sectores económicos poco explorados pero que muestran un crecimiento económico sostenido, a pesar de que todavía su cuota de participación en el producto interno bruto sigue siendo baja.

Por ello, el presente trabajo, pretende analizar la concentración de las PYMES por sectores económicos en la Provincia de El Oro, cómo esto afecta la tasa de crecimiento su económico, lo que demanda un replanteamiento de la función empresarial. En el mismo se plantea una revisión de la literatura, un análisis descriptivo del ingreso anual promedio por sector económico, tamaño promedio anual del mercado y su tasa de crecimiento, número promedio de empresas, valor agregado bruto de la provincia y sus componentes medidos por el lado de la producción. Para finalmente realizar un constructo teórico sobre el concepto de la función empresarial y el desarrollo de las conclusiones del estudio

\section{Función empresarial: aspectos de orden teórico}

La función empresarial nace a partir del surgimiento de las economías de escala como resultado de los avances logrados con la revolución industrial, el principio de la división del trabajo escrito por Smith (1982[1776]), Say (2001[1841]), Mill (1985[1848]) o Marshall (1963[1890]) y "Ley de asociación de Ricardo" (Ricardo, 1973[1950]). La producción moderna para que pueda ser posible requiere: 1) de grandes establecimientos productivos; 2) empresas que suministren materias primas; 3) empresas que suministren partes componentes; 4) la necesidad de incorporadores de partes componentes del producto final. Es decir, existe tanto una división del trabajo en la tarea específica como en los procesos.

Al respecto Mises (1996 [1949]) señala que la experiencia enseña al hombre que la acción mancomunada tiene una eficacia $y$ es de una productividad mayor que la actuación individual aislada. Las realidades 
Función empresarial y la concentración de las pymes en la Provincia de el Oro, Ecuador

naturales que estructuran la vida $y$ el esfuerzo humano dan lugar a que la división del trabajo incremente su productividad por unidad de esfuerzo invertido.

Por ello, las circunstancias naturales que provocan el aludido fenómeno de la división del trabajo; parte de la innata desigualdad de la capacidad de los hombres para realizar trabajos específicos, y la desigual distribución sobre la superficie de la tierra, de los recursos naturales. En ese orden de ideas Mises (1996[1949]) señala que la ley de asociación de Ricardo evidencia por qué desde un principio hubo una tendencia a ir gradualmente intensificando la cooperación humana, debido a que todo progreso hacia una más avanzada división del trabajo favorece los intereses de cuanto más en la misma participan. Se puede concluir que la acción humana estimulada por la percepción de la mayor productividad del trabajo bajo la división del mismo, permitió a la civilización progresivamente desarrollarse.

Con referencia a los orígenes de la sociedad, la tarea de la ciencia solo puede consistir en evidenciar cuáles sean los factores que pueden provocar la asociación. Para Mises (1996[1949]), la praxeología da cuenta de esos factores. Mientras el trabajo resulte más fecundo bajo el signo de la división del mismo y en tanto el hombre sea capaz de advertir tal realidad, la acción humana tendera espontáneamente a la cooperación y a la asociación (Mises, 1996[1949]). A tenor de ello, la ley de asociación de Ricardo, constituye una gravísima amenaza para quienes pretenden justificar el proteccionismo y el aislamiento económico, porque cada país se dedica aquellas ramas de la producción para las cuales sus específicas condiciones le ofrecen relativa, aunque no absolutamente, las mejores oportunidades (Mises, (1996[1949]).

En ese sentido, la ley de asociación, también conocida como el teorema del costo comparado, nada tiene que ver con la teoría del valor de la doctrina económica clásica. No alude ni al valor ni a los precios. Se trata de un juicio puramente analítico: sobre la productividad de los factores de producción, técnicamente posibles de trasladar, es diferente según los lugares donde se ubiquen y, de otro, que dichos factores, por razones institucionales tienen restringida su movilidad (Mises, (1996[1949]).

En un sentido general, la función empresarial coincide con la acción humana misma. Podría afirmarse que ejercer la función empresarial por cualquier persona es actuar para modificar el presente y conseguir sus objetivos en el futuro. Aunque esta definición a primera vista podría parecer demasiado amplia y no acorde con los usos lingüísticos actuales, hay que tener en cuenta que la misma responde a una concepción de la empresarialidad cada vez más elaborada y estudiada por la ciencia económica y que, además, es plenamente conforme con el significado etimológico del término empresa (Huerta de Soto, 2015). En efecto, tanto la expresión castellana empresa como las expresiones francesa e inglesa entrepreneur o enterprise proceden etimológicamente del verbo latino in prehendo-endi-ensum, que significa descubrir, ver percibir, darse cuenta de, atrapar; y la expresión latina in prehensa (Huerta de Soto, 2015).

Tomando en consideración lo antes expuesto, la economía ecuatoriana se encuentra sumergida en la trampa de la 
renta media, la cual según Domínguez y Caría (2016), se produce cuando los países muestran una incapacidad para completar la transición productiva desde los sectores de bajo nivel de valor agregado hacia sectores de alto nivel de valor agregado intensivos en tecnología. De allí que resulte de vital importancia la evolución positiva de la expansión y el crecimiento de las PYMES como eslabones fundamentales en la cadena productiva. Por ello, se hace necesario que las mismas reasignen los factores desde los sectores económicos de menor a los de mayor productividad; que las mismas se integren, colaboren y participen en el desarrollo de instrumentación de políticas nacionales que fomenten el capital humano, en particular la inversión en educación e innovación.

Para ello se hace necesario que el empresario ecuatoriano comprenda, como lo plantea Trincado (2009), que el valor de los bienes tiene una relación directa con la función empresarial en al menos dos sentidos. En primer lugar, si el valor depende de los costos, una parte consiste en el riesgo empresarial retribuido por el beneficio ${ }^{3}$. El beneficio del empresario es la clave para definir el papel que este juega en la sociedad donde está inmerso, su capacidad para crear valor como su función primordial y finalmente el crecimiento. En segundo lugar, los cambios en la economía en su conjunto, son los pilares fundamentales de la generación de riqueza mediante la acumulación de capital y el incremento en la disponibilidad de los factores de producción.

Por ser este quien selecciona los bienes que el mercado crea, en última instancia el que estima su valor en función de la utilidad percibida por el consumidor o bien en función de los costos de producción, a la espera de persuadir al consumidor de su utilidad. Convirtiéndose en el lazo fundamental entre valor y producción. Por ello para Trincado (2009), las teorías del empresario se basan en la teoría subjetiva del valor y en su caracterización de la acción humana y las preferencias intertemporales de los consumidores.

Siendo estos últimos quienes determinan el precio del mercado en función de la oferta y demanda de bienes y servicios; haciendo de los precios un registro histórico que le dice al empresario que cuando un bien sube de precio es porque hay una oferta insuficiente, que se convierte en una oportunidad de inversión, cuyo costo de oportunidad es menor al beneficio esperado; mientras si un bien baja de precio, quiere decir que hay un exceso de oferta y el costo de oportunidad de invertir en dicho sector de la economía es mayor al beneficio esperado.

No obstante, es importante que el empresario comprenda conceptos como costo de oportunidad, productividad marginal, nivel de valor agregado,

3 Idea desarrollada extensamente por el economista estadounidense Frank Knight (1964[1921]). Según Frank Knight, han existido diferentes concepciones de lo que es la ganancia a lo largo de la historia. En esa época, las corporaciones eran relativamente pequeñas y sin importancia desde el punto de vista económico; prácticamente estaban limitadas a pocos bancos y compañías comerciales; estaba surgiendo el crédito entre empresas, pero principalmente las corporaciones podían autofinanciarse y la función gerencial estaba centrado en el capitalista. Además, la competencia entre las empresas no estaba del todo desarrollada y lo más importante parecía ser la posesión de capital. Sin embargo, con la acumulación de capital, el incremento de la competencia entre las empresas y el mejoramiento de los métodos y procesos bancarios transfirieron el centro de interés del capitalista a las habilidades del denominado "hombre de negocios". 
Función empresarial y la concentración de las pymes en la Provincia de el Oro, Ecuador

asignación de los factores de producción, riesgo, entre otros conceptos afines. Donde el mismo debe apostar por actividades productivas que agreguen mayor valor en los distintos sectores de la economía, aunque ello implique mayores riesgos en la inversión. Al mismo tiempo la utilidad marginal obtenida por el consumidor por cada unidad adicional adquirida y producida sería mayor en la medida que se agrega más propiedades. El resultado debería ser una mayor demanda de mayores unidades producidas y por ende el beneficio esperado por el empresario.

Lo antes expuesto, llevado a escala social, producirá un efecto favorable para la sociedad, ya que en la medida que su actividad productiva genera mayor valor, mayor será la necesidad de empleo de factores productivos como el trabajo, produciéndose un incremento de los salarios reales y del nivel general de empleo; mayores contribuciones al fisco por la vía impositiva y mayores niveles de responsabilidad social para con la sociedad en la cual está inserto.

Ahora bien, el fracaso empresarial deacuerdoaRomeroEspinoza, Melgarejo y Vera-Colina (2015), se produce debido a factores externos como disponibilidad de mecanismos de crédito, la densidad de los tramites administrativo, el número de regulaciones estatales, el nivel de presión fiscal y tributaria, las relaciones con las instituciones estatales, créditos con proveedores y sector financieros; finalmente eficiencia de los canales de distribución y comercialización. Ahora bien, también existen factores de carácter interno, problemas de liquidez y solvencia que les dificulta atender sus obligaciones financieras, bajos márgenes de rentabilidad que se traducen en un valor reducido de los activos o escasez del flujo de caja, que terminan decantando en suspensión o incumplimiento de pagos. En general todos estos factores antes señalados son los que pueden explicar las altas tasa de mortalidad de PYMES.

En sentido, si se instrumentasen políticas económicas sectoriales que les garantizase un ingreso estable y con tendencia creciente a dichas empresas, al relocalizarlas en sectores productivos más rentables previas capacitación y formación, esta tasa de mortalidad bajaría, y los sectores económicos sujetos de desconcentración como el comercio y servicios, incrementarían sus márgenes de rentabilidad y niveles de ingreso.

De allí la importancia de incluir las PYMES en sectores tan vitales para la economía como el de la manufactura, según Jiménez y Rodríguez (2017), mediante un esquema de apertura comercial de última generación que sirven de catalizadores para el incremento de la dinámica industrial en términos de ventas, ampliación de infraestructura, exportaciones, acceso de insumos especializados de menor costo y tecnología, que permitan un escalamiento en actividades de mayor valor agregado.

Escalamiento que solo puede lograrse mediante el empleo de la tecnología de manera que permita elevar los niveles de productividad tal como lo señalan Ibujes y Benavides (2017), considerando por ser una herramienta fundamental en la gestión empresarial que hace más eficiente, eficaz y competitivas a las empresas. Siendo las PYMES de la industria textil en el Ecuador según los referidos autores un ejemplo de la relación entre el grado de productividad alcanzado y el uso de la tecnología empleada. En el cual la PYMES para el año 2016 contribuyeron 
con $50 \%$ del empleo nacional, y entre 2007 y 2013 estas tuvieron un crecimiento de $41 \%$ pasando de 66.000 a 93.000 PYMES en el mismo periodo el volumen de ventas creció un $60 \%$ alcanzando los 208 millones de dólares.

El estudio de Ibujes y Benavides (2017) señala que la industria textil para el periodo 2000-2014 se encontraron evidencias que la productividad se ve influenciada por el uso de la tecnología, seguido del capital físico y humano, aunque el modelo econométrico de Solow empleado muestra rendimientos decrecientes a escala, lo que significa que un incremento en la proporción de los factores de producción (capital, trabajo y tecnología) asignados para producción terminarían elevando esta, pero con tasas de crecimiento cada vez menores. No obstante, se comprobó la hipótesis del efecto positivo que tiene el uso de la tecnología en la productividad de las PYMES del sector textil porque se invierten en insumos tecnológicos y se modernizan líneas de producción, mediante la adquisición de nuevas maquinarias y equipos de cómputo.

Sin embargo, el estudio señala la necesidad de que se desarrolle o actualice un marco legal que fomente el desarrollo industrial de las PYMES ecuatorianas, para en el mediano y largo plazo lograr un cambio en la matriz productiva. Esta depende en gran medida de la desconcentración de PYMES en sectores de la economía con bajo valor agregado como sector comercio y servicios, para lo cual el uso de la tecnología y la capacitación y formación del capital humano para su empleo eficiente juegan un papel fundamental.

Así mismo, se requieren para ello modelos de asociatividad en las cadenas productivas tal como lo plantean Bada,
Rivas y Littlewood (2017), con la finalidad de establecer en qué medida los actores directos en materia de soporte técnico y servicios conexos que básicamente son prestados por las PYMES, unido al apoyo institucional del estado pueden contribuir apalancar el aumento de la producción en los diferentes sectores productivos en los cuales intervienen, de allí la importancia de las relaciones entre empresas y las políticas económicas sectoriales del gobierno que son quienes terminan definiendo la asociatividad en la cadena productiva.

Los referidos autores señalan que una estrategia fundamental para el desarrollo de la pequeña y mediana industria a raíz del proceso globalizador, es la necesidad de fomentar la asociatividad entre las empresas de un mismo sector económico que comporten características y valores comunes, promoviendo la creación de conglomerados y redes empresariales en cadenas productivas, que facilitan los procesos de cooperación empresarial y social a través de los mecanismos de oferta y demanda del mercado, donde cada participante puede competir organizada y libremente para captar una cuota de mercado que le permita ir escalando hacia actividades de mayor valor agregado en la cadena productiva.

La cual surge de acuerdo a Bada, Rivas y Littlewood (2017) como una alternativa de eficiencia colectiva fundamentada en políticas macroeconómicas coherentes, que identifican previamente las ventajas competitivas y las características socioeconómicas del entorno, en aras generar un clima de estabilidad y confianza que facilite las actividades de producción, los procesos de transformación de materias primas en bienes de consumo intermedio, o de 
Función empresarial y la concentración de las pymes en la Provincia de el Oro, Ecuador

estos últimos en bienes finales, hasta llegar al consumidor final. Para lo cual resulta vital el suministro de materias primas, la adquisición de bienes de capital, las fuentes financiamiento de capital, las actividades de investigación y desarrollo y la asistencia técnica, entre otras, las cuales resultan fundamentales para la generación de riqueza material e incrementar el nivel de bienestar social.

Este proceso de asociatividad se potencializa en la medida que las capacidades de absorción del conocimiento como ventajas competitivas en las PYMES permiten su inserción en las cadenas globales de valor, tal como lo señala Miranda, Contreras y Barcelo (2015) quienes plantean la necesidad de identificar estas capacidades y proponen un modelo basado en dos enfoques teóricos, los sistemas de innovación y las cadenas globales de valor. En su estudio realizado al noroeste de México en los sectores de tecnologías de información y metalmecánica, los hallazgos encontrados evidencian que cuando las PYMES locales prestan servicios de apoyo técnico y de logística a las grandes empresas transnacionales, estas reciben transferencias de conocimiento que les permite escalar en la cadena de valor con actividades de mayor valor agregado.

En este sentido, Yance, et al. (2017) destacan que las ciudades del Ecuador tienen un acelerado crecimiento y desarrollo en lo concerniente a las PYMES. Sin embargo, estas deben enfrentar la competencia de grandes empresarios con poder económico que provienen de ciudades grandes, quienes se diferencian por su alto nivel de productividad el cual es alcanzado por la correcta aplicación de la administración de operaciones en sus procesos, aspecto que las pone en desventaja.
Con respecto a ello, Ron y Sacoto (2017:5) resaltan que: "en Pichincha y Guayas se encuentran la mayor cantidad de PYMES, esto debido a la concentración de la población en estas localidades, así como de las empresas más grandes, a las que las PYMES proveen de bienes y servicios, en gran medida especializados (Soporte técnico en materia de Telecomunicaciones, administración de redes de área local, desarrollo y soporte de sistemas de información, reparación y mantenimiento de maquinaria, suministro de insumos para la producción y consumibles)". Otro de los motivos que explican la gran cantidad de PYMES en las provincias de Pichincha y Guayas es la concentración de líneas de microcrédito en dichas provincias, según datos de la Superintendencia de Bancos del Ecuador en el año 2015 la colocación de microcréditos a nivel nacional tuvo una participación de $7,86 \%$ respecto al total de cartera colocada en el país por los bancos privados, de éste porcentaje $73,88 \%$ de microcréditos se desembolsaron en las dos provincias antes mencionadas (Peña y Vega, 2017).

Según datos del INEC (2016), reportados por Delgado y Chávez (2018), señalan que en el Ecuador actualmente se encuentran alrededor de 179.830 PYMES, distribuidos así: 1) la provincia de Guayas con $32,57 \%$ que representa un total de 58.574 empresas de este tipo; 2) la provincia de Pichincha con $27,95 \%$ equivalente a una cantidad de 50.269 PYMES; 3) la provincia de Manabí con $5,54 \%$ que equivale a 9.970 empresas; 4) la provincia de Azuay con 4,69\% y 8.438 empresas; y 5) El Oro con 4,21\% y 7.567 PYMES. En consecuencia, estas cinco provincias suman alrededor de 135.000 PYMES que equivale a un alto porcentaje sobre el total nacional. 
En el año 2010, Peña y Vega (2017) expresaron que las PYMES contribuyeron en la generación de $67 \%$ del total de ingresos de la economía. No obstante, de los aportes de las PYMES en el desarrollo de la economía, se puede señalar que este tipo de empresas no ha experimentado un crecimiento armónico a lo largo del país. Así, en promedio $85 \%$ de PYMES se concentra en las ciudades de Quito y Guayaquil, lo que podría provocar que en el país se establezca o profundice un modelo "Centro - Periferia".

En el caso del sector urbano de la ciudad de Quevedo, Ecuador, la actividad económica que predomina es la comercial con un $57,22 \%$, le sigue las actividades de servicios con un $34,18 \%$ y las industrias manufactureras con un 8,53\% (Arguello, 2018:8). Por su parte, Yance, et al. (2017:2) afirman que las PYMES son fuente generadora de empleo en el Ecuador, siendo necesario que las mismas logren alcanzar un desarrollo sostenible en el tiempo a través de procesos y productos de calidad. En el país, 39\% de los empleos son generados por microempresas, mientras que $17 \%$ a pequeñas y $14 \%$ a medianas (Jácome y King, 2013; citados por Ron y Sacoto, 2017:5).

Razón por la cual Gomero (2015) señala que la sostenibilidad de la rentabilidad de los negocios, depende de un conjunto de factores clave: ubicación, la carga tributaria, el costo de transporte, la dimensión de mercado, entre otros. En tal sentido, destaca Gomero (2015) que en el caso de Lima (Perú), centraliza $47,3 \%$ de las empresas, es decir, de cada 100 empresas formadas a nivel nacional 47 centran sus operaciones en la ciudad capital, y si a esta cifra se le suma las de Callao, se llega al $50 \%$, convirtiéndose esta región en la gran aportante de riqueza del país o en la formación del PIB, obedeciendo esta centralización a factores que en los departamentos del país no se puede encontrar, convirtiéndose esta situación en un alimentador de la pobreza en aquellas regiones que no se ven beneficiadas con esta dinámica empresarial. Al respecto, esta misma configuración se presenta a nivel de microempresas, cuyas cifras evidencian una fuerte concentración en Lima Metropolitana, cuyo grado de participación llega a 46,8\%.

En la concentración de las microempresas y de los pequeños negocios, resalta Gomero (2015) que, en el caso de Lima, está explicado por los siguientes factores: 1) el mercado, 2) el tipo de mano de obra, 3) los proveedores, 4) las entidades administrativas del gobierno; y 4) la infraestructura económica. Al mismo tiempo, cualquiera que sea la estructura organizativa, estas empresas desarrollan sus actividades mayormente en el sector comercio y servicio, seguido de la actividad manufacturera, llegando las microempresas que se dedican al sector comercio a $47 \%$, mientras que las empresas dedicadas a la actividad manufacturera tienen una participación del $9 \%$. El comercio es la actividad que se ha potenciado en los últimos años, aglomerando una importante cantidad de mano de obra, específicamente no calificada.

Lo señalado anteriormente con la ciudad de Lima, evidencia la propensión de las personas por formar empresas que solo realizan actividades de intermediación comercial, sin generar valor agregado y contribución efectiva a la formación del PIB. Otra actividad que destaca es la de servicios profesionales, segmento empresarial que se dedica al servicio de asesoría empresarial, siendo 
Función empresarial y la concentración de las pymes en la Provincia de el Oro, Ecuador

su aporte a nivel de las microempresas de 9,9\%. Estas cifras generan espacios laborales e ingresos a favor de los actores económicos, pero su contribución al desarrollo regional es marginal, ya que solo son actividades comerciales con mínimos efectos multiplicadores de tipo económico y social (Gomero, 2015:35).

Por su parte, Romero, Melgarejo y Vera-Colina (2015) señalan que la concentración de PYMES en Colombia se encuentra principalmente en la ciudad de Bogotá y en los departamentos como Antioquia, Valle del Cauca y Cundinamarca. Se considera a Bogotá como el principal centro de negocios nacional, con una participación en el PIB de $24,4 \%$, siendo las ramas de actividad con mayor participación: 1) los establecimientos financieros, seguros actividades inmobiliarias, y servicios a las empresas representan 36,8\%; 2) los servicios sociales, comunales y personales con 19,3\%: 3) comercio, reparación, restaurantes y hoteles $15,5 \%$; y 4) la industria manufacturera contribuye con $10,3 \%$. Asimismo, el tejido empresarial de la ciudad se caracteriza por una amplia base de microempresas $(87 \%)$ y se encuentra el mayor número de pequeñas $(9 \%)$ y medianas empresas (4\%) y grandes empresas (1\%) (Romero, Melgarejo y Vera-Colina, 2015).

En Colombia, el sector de comercio concentra $42 \%$ de las empresas colombianas y el de servicio $40 \%$, le siguen la industria con $13 \%$ y la construcción con 6\%. En general, la participación de las PYMES en el valor agregado de la industria se ha mantenido constante, con un ligero aumento de la participación de las pequeñas en $4,4 \%$ y de las medianas en $2,7 \%$ durante el período 1992-2015. La productividad laboral de los micro- establecimientos por sector muestra que el sector comercio tiene en promedio la mayor productividad de los tres sectores, seguido por la industria y los servicios. Una microempresa industrial produce en promedio un poco más de una décima parte que la empresa grande, mientras que las PYMES producen alrededor de la mitad (Gómez y Borda).

En el caso de México, del total de empresas, el comercio representa $48,3 \%$, los servicios $38,7 \%$, manufactura $11,6 \%$ y otras actividades económicas 1,4\%. El peso de las MIPYMES en la producción total (en términos de producto interno bruto) es reducido y contrastante a la contribución de $72,3 \%$ de las grandes empresas. En consecuencia, a nivel de los sectores económicos, se cuenta con una mayor proporción de MIPYMES en el sector comercio y servicios en términos de cantidad de empresas y una mayor capacidad empleadora en el sector comercio y en menor medida, del sector servicios. El sector manufactura por su parte, se caracteriza por contar con una mayor proporción de empresas grandes respecto al resto de los servicios que emplean a más de la mitad de los trabajadores del sector (Stezano, 2018).

Esta situación evidencia que la participación más relevante de las MIPYMES (micro y pequeñas especialmente) se da en las ramas con menor productividad (comercio y servicios), de menores barreras de entrada y bajos incentivos para desatar articulaciones productivas con otras empresas o agentes de la innovación. Por ello, la presencia predominante de las MIPYMES en esos sectores reduce notoriamente las oportunidades para generar externalidades que permitan aumentar la especialización empresarial y de la fuerza laboral, y la propensión a 
la innovación y productividad (Stezano, 2018).

\section{Consideraciones metodológicas de la investigación}

El tipo de investigación que se presenta es de carácter descriptivo, el cual según Marczyk, DeMatteo \& Festinger (2005) consiste en definir, clasificar o categorizar los fenómenos de interés, proporcionado información importante acerca de las características del sujeto u objeto de estudio y sus relaciones con el entorno. En el caso de la presente investigación se describen los Ingresos anuales promedio de las micro, pequeña y mediana empresa $A$ o B en la provincia de El Oro, al igual que el tamaño anual promedio del mercado de las pymes de acuerdo a cada sector económico y el número promedio de empresas, el volumen de ventas anuales de todos los sectores económicos, el tamaño del PIB real por sectores económicos en términos promedios y el valor del PIB a precios constantes y la tasa de crecimiento anual de sus componentes por el lado de la producción para el periodo sujeto a estudio.

Así mismo, el estudio se considera correlacional porque mide el coeficiente de elasticidad y determinación del consumo intermedio respecto a la producción y el valor agregado bruto real en aras determinar como la variación del consumo intermedio impacta la variación de la producción total y del valor agregado bruto real, así como también el porcentaje de la varianza de estas dos últimas que es explicada por el consumo intermedio en aras de construir un indicador de productividad. Los estudios correlacionales tienen como objetivo descubrir o establecer la existencia de una relación / asociación / interdependencia entre dos o más variables de investigación (Kumar, 2011).

Se siguió un diseño no experimental debido a que no existió la manipulación deliberada de variables de investigación, los investigadores solo se circunscribieron a describir las variables sujeto de interés para el estudio, tomadas de las fuentes de información secundaria Bernal (2006), para luego establecer algunas asociaciones entre ellas, para finalmente proponer un mapa conceptual donde se exponen los elementos esenciales de una función empresarial eficiente, a partir de los preceptos teóricos de Friedrich Von Hayek tomados de social Huerta de Soto (2015).

Esto permite señalar que el presente estudio se inserta dentro del paradigma positivista o cuantitativo, el cual es un modelo epistémico derivado del empirismo, que a su vez emana del realismo, que es el modelo originario Ortiz (2015). Es una doctrina filosófica cuya única realidad concebida, es la que está sustentada por los hechos. De allí que la labor de la filosofía consista en comprender los métodos que permiten el avance de las ciencias a través del proceso de verificación científica mediante la cosmovisión del investigador el cual relaciona y contrasta el fenómeno sujeto a estudio con el basamento teórico del que dispone para confirmar o rechazar las hipótesis de investigación, por lo que el positivismo objeta toda intuición directa del conocimiento, toda metafísica, todo conocimiento a priori. 
Función empresarial y la concentración de las pymes en la Provincia de el Oro, Ecuador

\section{Función empresarial y concentración de pequeñas y medianas empresas en la Provincia de El Oro - Ecuador: Resultados}

Para los efectos del presente estudio, al analizar los ingresos anuales promedios del periodo 2007-2017 según datos del INEC (Instituto Nacional de Estadísticas y Censos, 2019) en el sector de las micro y pequeñas empresas, las unidades de producción cuya actividad económica se encuentra en los sectores de agricultura, ganadería, silvicultura y pesca, explotación de minas y canteras y construcción presentan mayores niveles de ingresos en términos nominales, tal como se muestra en el gráfico 1, luego le siguen comercio, manufacturas y servicios.

\section{Gráfico 1 \\ Ingresos anuales promedio de una microempresa y pequeña empresa de acuerdo al sector económico en la Provincia de EI Oro 2007-2017}

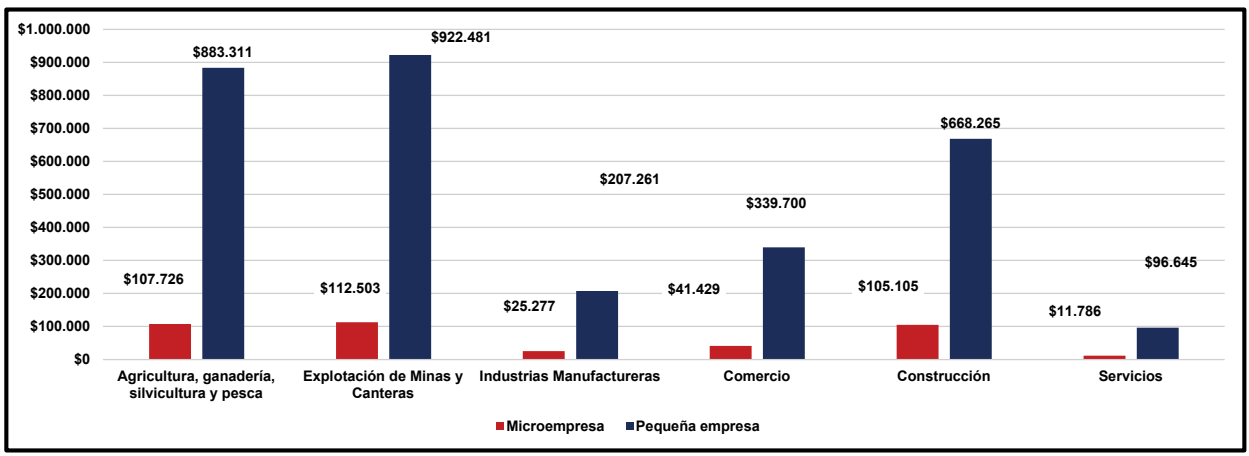

Fuente: Instituto Nacional de Estadísticas y Censos (2017)

Lo mostrado en el gráfico 1 también permite evidenciar dónde se concentran los mayores niveles de inversión, así mismo, pudiera aducirse que son los sectores donde existen menores niveles de competitividad, como es el caso del sector minas y canteras al igual que de construcción, manufacturas y agricultura, ganadería y silvicultura, como se verá más adelante en el gráfico 4, por presentar un menor número de unidades de producción.
Es decir, la actividad económica de la pequeña empresa va pari passu con la vocación económica de las regiones en donde se encuentran ubicadas. Esa vocación económica se sustenta en elementos tradicionales y sobre todo que, para el tamaño de las explotaciones, tienen cierto grado de rentabilidad. En resumen, se está frente a un ejemplo de dificultad de transcender sectores de bajo valor agregado a sectores con alto valor agregado como lo advierte 
Trincado (2009).

Igualmente, en los sectores de las medianas empresas $A$ y $B$, tal como se muestra en el gráfico 2 en concordancia con lo expuesto en el gráfico 1, las organizaciones empresariales que se desempeñan en las áreas productivas de construcción, explotación de minas y canteras y agricultura, ganadería, silvicultura y pesca, son las que presentan mayores niveles de ingresos nominales promedios anuales; lo cual pudiera explicarse por varias razones: 1) mayores márgenes de inversión $y / o$ valor agregado; y 2) sumado a menores niveles de competitividad. Luego sigue comercio, los servicios y manufacturas donde sin duda alguna existen mayores niveles de competitividad, ya que son las actividades económicas de la provincia de El Oro donde existen un mayor número de unidades de producción.

\section{Gráfico 2 \\ Ingresos Anuales Promedio de una Mediana Empresa "A" y "B" de Acuerdo al Sector Económico en la Provincia de El Oro 2007- 2017}

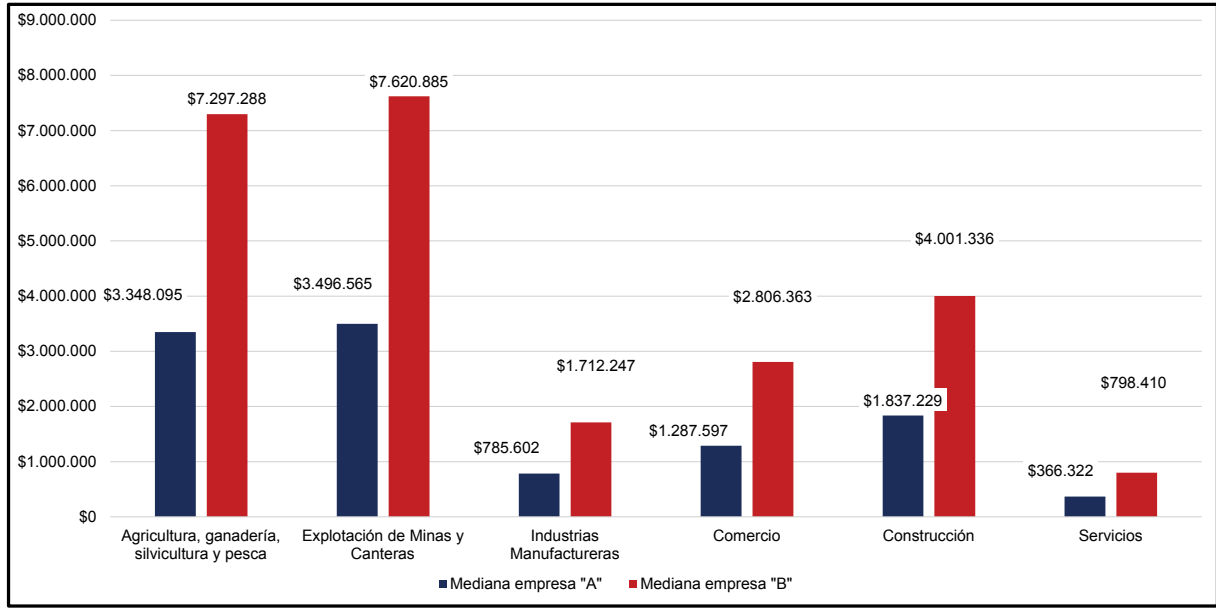

Fuente: Instituto Nacional de Estadísticas y Censos (2017)

Finalmente, lo que puede sintetizarse luego de analizar los gráficos 1 y 2 es que las oportunidades de inversión y expansión del mercado para la pequeña y mediana industria están en los sectores de agricultura, ganadería, silvicultura y pesca, explotación de minas y canteras, manufacturas y construcción.
Por su parte, sectores como el comercio y servicios están consolidados $\mathrm{y}$, por tanto, la apuesta debe ser por un cambio en la matriz productiva apuntando el sector primario y manufacturero, en aras de producir la expansión del mercado mediante un mayor nivel de valor agregado. De no darse lo anterior, 
Función empresarial y la concentración de las pymes en la Provincia de el Oro, Ecuador

se estaría produciendo una división del mercado.

Los gráficos 1 y 2 muestran al menos cuatro cosas: 1) lo ya adelantado por Trincado (2009); 2) la existencia de una débil función empresarial que teme tomar riesgos de inversión en sistemas productivos que generen mayor valor agregado, se invierte en lo seguro; 3) carencia de políticas nacionales, provinciales o locales para incentivar la migración a sectores generadores de mayor valor agregado; y 4) la competencia con los grandes centros industriales de Ecuador como Quito y especialmente Guayaquil tal como lo asoman Ron y Sacoto (2017) y Peña y Vega (2017).

En síntesis, es una combinación de asumir riesgos económicos-financieros junto a políticas públicas que garanticen estabilidad y continuidad en el largo plazo. No obstante, antes que nada, el empresario está claro de la vocación económica de una determinada región y sus potencialidades en cuanto a disponer de factores productivos. Es decir, la actividad económica a desarrollar debe ser rentable, debe ser negocio: que el cliente vea satisfecha sus necesidades en términos de utilidad marginal y el empresario en términos de beneficio marginal.

De acuerdo al gráfico 3 , el tamaño anual promedio del mercado de las PYMES de acuerdo a cada sector económico, el comercio, la agricultura, ganadería, silvicultura y pesca contribuyen con $27 \%$, el sector comercio con $49 \%$ y los servicios con $12 \%$; mientras que la explotación de minas, industria y construcción solo contribuyeron con apenas $12 \%$.

\section{Gráfico 3}

\section{Tamaño Anual Promedio del Mercado de las PYMES de Acuerdo a cada Sector Económico en la Provincia de El Oro 2007-2017}

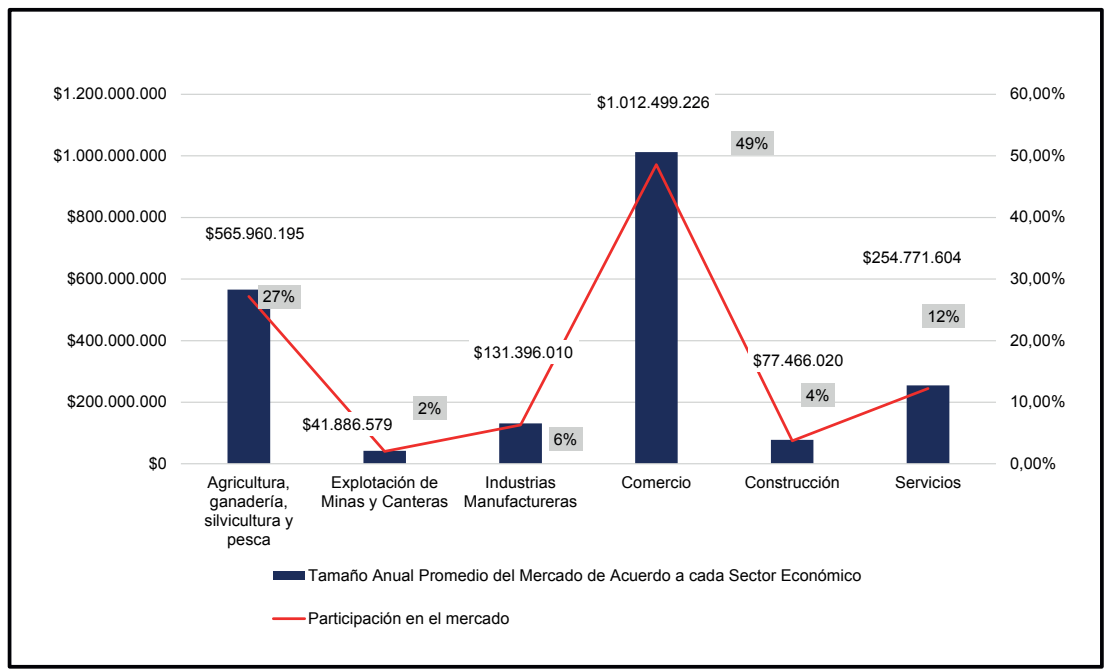

Fuente: Instituto Nacional de Estadísticas y Censos (2017) 
Evidentemente, estos sectores responden a la vocación económica de la región y, por tanto, cumplen con la idea de que el beneficio marginal es superior al costo marginal (Trincado, 2009) independientemente del modelo de mercado prevaleciente. Además, según este autor, el costo de oportunidad $^{4}$ de desprenderse de este tipo de sector para incursionar, por ejemplo, en la manufactura es muy alto y hasta prohibitivo. Desde el punto de vista económico financiero, la empresa tendría que cambiar su estructura financiera, por cuanto tendría que emigrar de un sector donde los activos circulantes son más importantes a un sector donde el activo fijo neto sería el componente principal. Sin embargo, la demanda sobre el capital de trabajo en la manufactura es altamente exigente, lo cual implicaría un financiamiento constante a corto plazo (Borgucci, 2013). Por otra parte, cambiar de la actividad del negocio a la manufactura implica que el pasivo a largo plazo se convertiría en un componente relativo muy significativo, por lo que la empresa tendría contar con un alto poder de generar ganancias y cargar crónicamente sus utilidades y abonarlas a capital pagado y reservas (Borgucci, 2013).

De acuerdo a lo mostrado en el gráfico 4 el, número promedio de PYMES establecidas en cada sector económico se encuentran establecidas en el sector comercio y servicios, representando $53 \%$ de la participación en el mercado del sector servicios y $28 \%$ en el área de comercio. Después, se encuentran el sector de industrias manufactureras y construcción quienes representan el $7 \%$ y $6 \%$ de sus respectivos mercados. Finalmente, se encuentran los sectores de agricultura, ganadería, silvicultura y pesca, así como el de explotación de minas y canteras, quienes representan apenas $5 \%$ y $1 \%$ de la participación del mercado.

4 La idea de costo de oportunidad se le atribuye a Friedrich von Wieser, que la dio a conocer en su trabajo de habilitación denominado: Über den Ursprung und die Hauptgesetze des wirthschaftlichen Werthes (Sobre el origen y principales leyes económicas del valor) de 1884. Al resolver el problema de la imputación (Zurechnung), queda establecido que el valor de los bienes superiores se imputan a los de primer orden. Pero esta utilidad marginal imputada sirve como costo de oportunidad o en qué medida un bien de orden superior complementará o sustituirá a otro bien de orden superior en el proceso de producción de un bien de primer orden. En términos de Hayek: “.... sobre la relación entre costes y valores a la luz de la teoría subjetiva del valor le llevan a considerar los costes como utilidad indirecta (costes de oportunidad), sobre la base de una presentación detallada de la utilidad media de la producción. Desde Pantaleoni, esta forma moderna de la ley de los costes se conoce merecidamente como «ley de Wieser" (Hayek, 1996[1992]:121). 


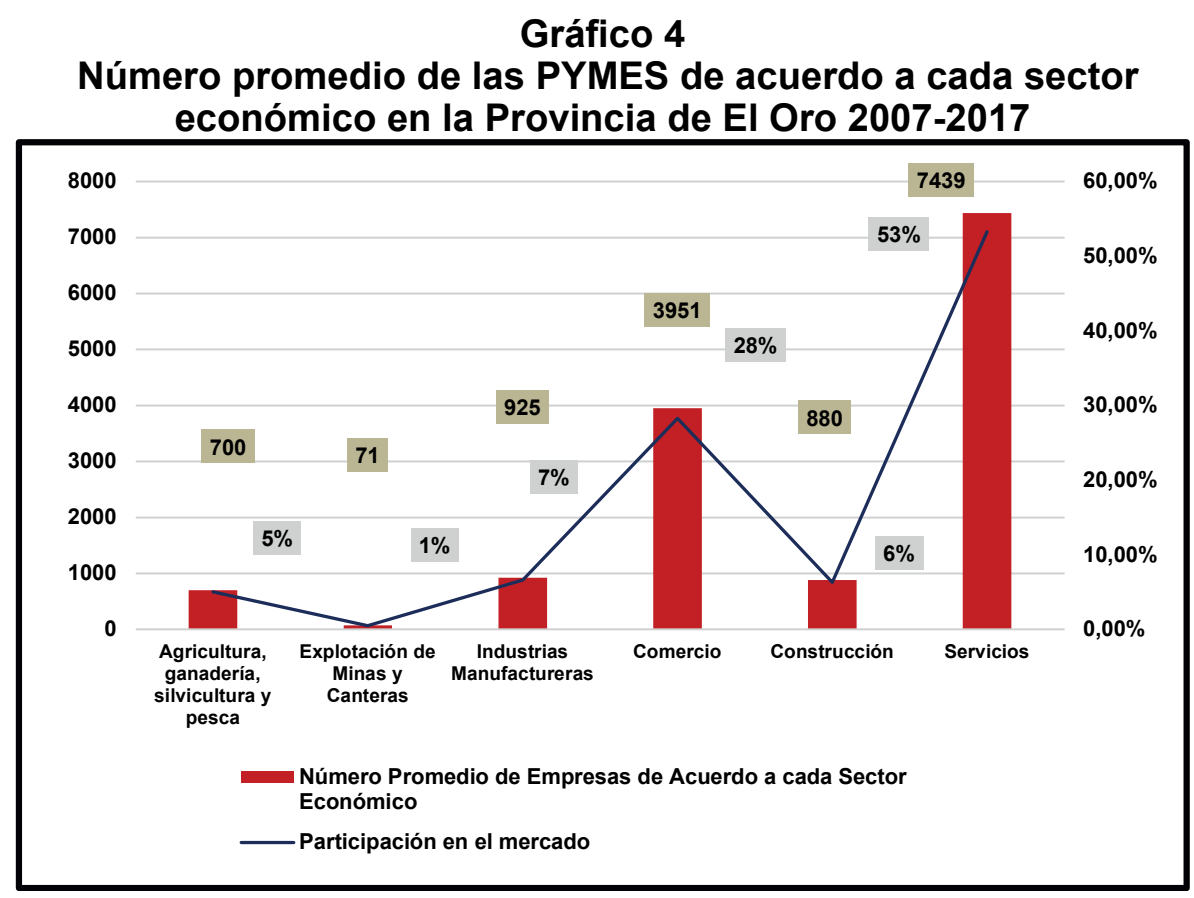

Fuente: Instituto Nacional de Estadísticas y Censos (2017)

Los resultados anteriores muestran la importancia de las PYMES en la creación de empleo en una economía en un país en vías de desarrollo como Ecuador. No obstante, también es una señal inequívoca de las debilidades del crecimiento económico y del lento crecimiento de las remuneraciones de cientos de miles de personas que trabajan en sectores que aportan una rentabilidad relativa baja y cuya productividad es débil. En este sentido, nuevamente, las grandes empresas, tal y como sostienen Yance, et al. (2017) son quienes aportan más el crecimiento del producto interno bruto. Estas empresas, lamentablemente se encuentra en centros urbanos de gran tamaño como Quito y Guayaquil (Ron y Salcedo,
2017). Esto último contribuye a la concentración del desarrollo económico en las dos áreas metropolitanas antes mencionadas tal y como lo aseveran peña Vélez y Vega (2017).

Es decir, el desarrollo de las PYMES estará condicionado, a parte de una buena legislación que las promocione, de altos niveles de ganancias en el largo plazo y de una alta demanda de inversiones cuya salida sea principalmente la generación de economías de escala y de producción totalmente exportable. Es decir, las PYMES deberán cambiarse de ser productoras de bienes no transables a bienes transables básicamente desde su propio poder de generar ganancias para ganar credibilidad en el mercado de 
fondos prestables.

En el gráfico 5, se muestran las oportunidades y potencialidades que requieren con prontitud explotarse al máximo en un mercado como el de la provincia de El Oro. En efecto, en el gráfico se muestra en el tamaño del mercado (Ventas totales de los sectores económicos), que, si bien muestra una tendencia en términos absolutos crecientes con un incremento anual promedio de más de 430 millones de dólares, la tasa de crecimiento del total de las ventas en los diferentes sectores económicos en términos promedios es decreciente.

\section{Gráfico 5}

\section{Tamaño del mercado (Ventas totales de los sectores económicos) en la Provincia de El Oro 2007-2017}

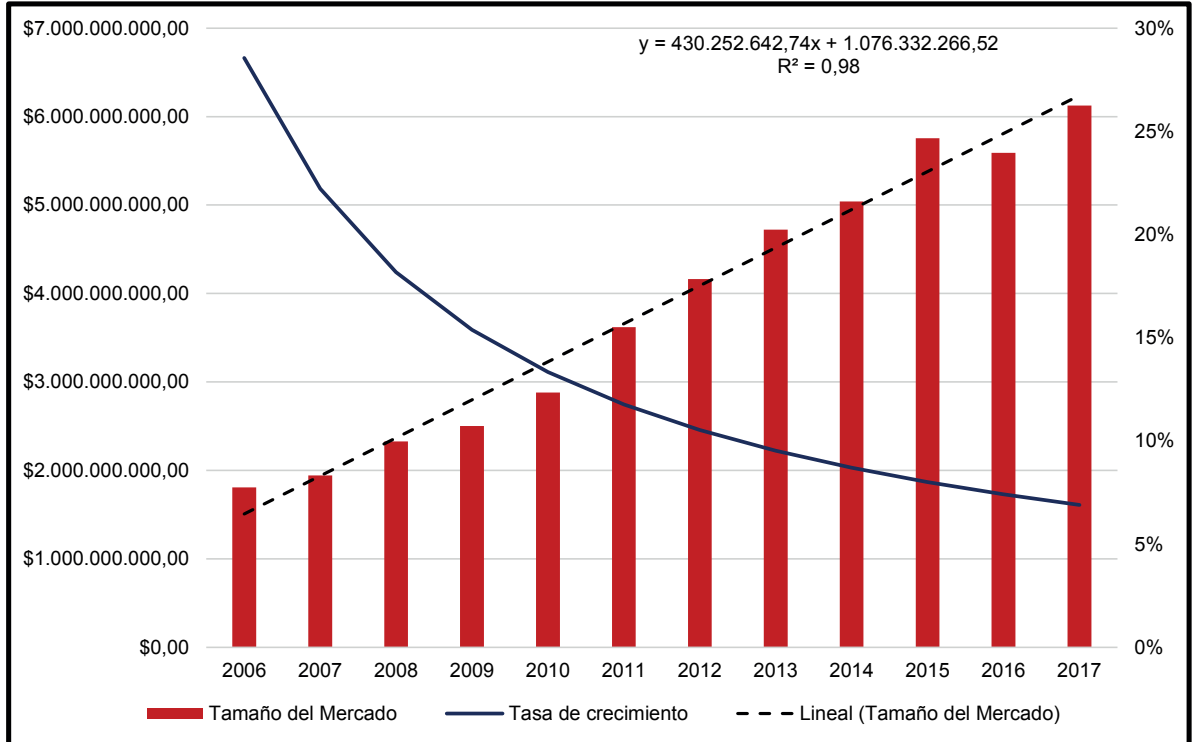

Fuente: Instituto Nacional de Estadísticas y Censos (2017)

Ello evidencia las considerables limitaciones que tiene la economía para mantener un aumento sostenido de las ventas, ya que las mismas están concentradas en los siguientes sectores: agricultura, ganadería, silvicultura, pesca, comercio y servicios. Por esta razón, se debe buscar diversificar la economía aprovechando las potencialidades $y$ agregando mayor valor en áreas como la explotación de minas, canteras y la manufactura que, de acuerdo al gráfico 6 , son las que muestran mayores tasas de crecimiento promedio con $12 \%$ y $10 \%$ respectivamente, a pesar de que ambas solo representan cada una en términos promedio el $4 \%$ del PIB de la provincia de El Oro. 


\section{Gráfico 6}

\section{Tamaño del PIB por sectores económicos a precios constantes en la Provincia de El Oro 2007-2017}

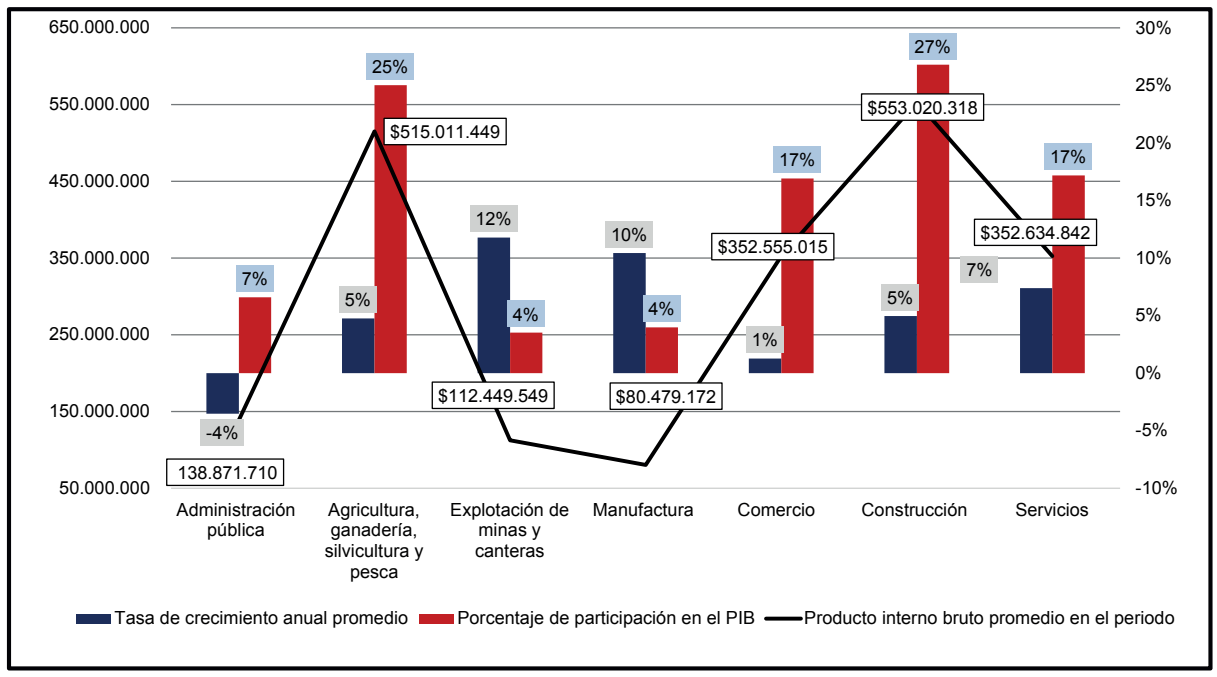

Fuente: Instituto Nacional de Estadísticas y Censos (2017)

Lo antes expuesto, permitiría dinamizar la economía, crear mayores fuentes de empleo, elevar las tasas de crecimiento de la producción total, el valor agregado bruto en términos reales y obtener mayores tasas de crecimiento. Lo antes dicho mejoraría el comportamiento del PIB real de la provincia, ya que apenas se incrementa en unos 84,3 millones de dólares anuales como se muestra en el gráfico 7 . Lo anterior representa apenas un $4 \%$ de crecimiento anual en valores promedio, en tanto la tendencia de las tasa de crecimiento del consumo intermedio, producción y PIB real es decreciente como se puede observar también en el gráfico $n^{\circ} 7$. De acuerdo a la tendencia antes citada, en algunos años la tasa de crecimiento el consumo intermedio supera a la del valor agregado bruto y producción total, lo que explicaría, sin duda alguna, cómo a partir del año 2012, todas caen por debajo del $4 \%$, dándose de manera acelerada una tendencia al estancamiento económico. 
pp. 776-801

Revista Venezolana de Gerencia, Año 26 No. 95, 2021

\section{Gráfico 7}

\section{Valor del PIB a precios constantes y la tasa de crecimiento anual de sus componentes por el lado de la producción en el periodo 2007-2017}

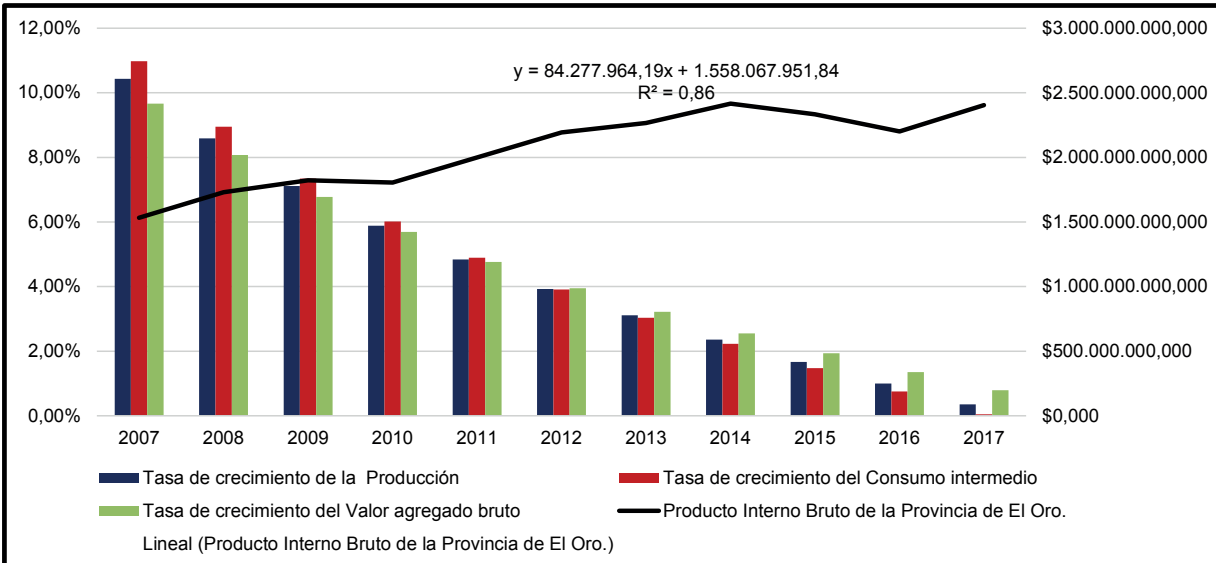

Fuente: Instituto Nacional de Estadísticas y Censos (2017)

El problema de productividad señalado en el análisis del gráfico 7, mediante la caída de la tasa de crecimiento del PIB real en forma progresiva, se evidencia nuevamente en el gráfico 8.

\section{Gráfico 8 \\ Consumo intermedio vs PIB real y Producción Total}

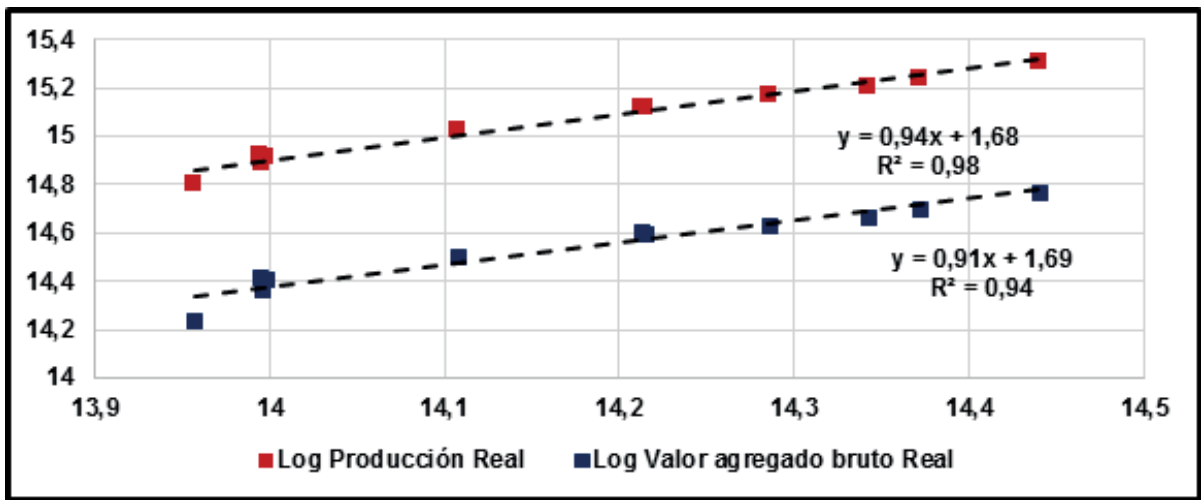

Fuente: Instituto Nacional de Estadísticas y Censos (2017) 
Urdaneta Montiel, Armando José; Borgucci Garcia, Emmanuel Vitorio; González Ordóñez, Andreina Inés; Luciani Toro, Laura Rosa

Función empresarial y la concentración de las pymes en la Provincia de el Oro, Ecuador

Al llevar las variables a logaritmos, y donde el coeficiente de elasticidad del consumo intermedio versus el PIB real y producción total es igual a la pendiente de la recta de regresión lineal; es decir un incremento del $1 \%$ del consumo intermedio ${ }^{5}$, solo produce un incremento del $0,94 \%$ de la producción y $0,91 \%$ del valor agregado bruto. Vale decir, el rendimiento delos insumos empleados en la producción es menos que proporcional al producto creado.

Todo el escenario antes relatado lleva a replantearse que, para la provincia de El Oro, el concepto de la función empresarial con base a lo expuesto por Huerta de Soto (2015) y Mises (1982[1912]) se integran gráficamente en el diagrama 1.

\section{Diagrama 1}

\section{Elementos de la función empresarial eficiente}

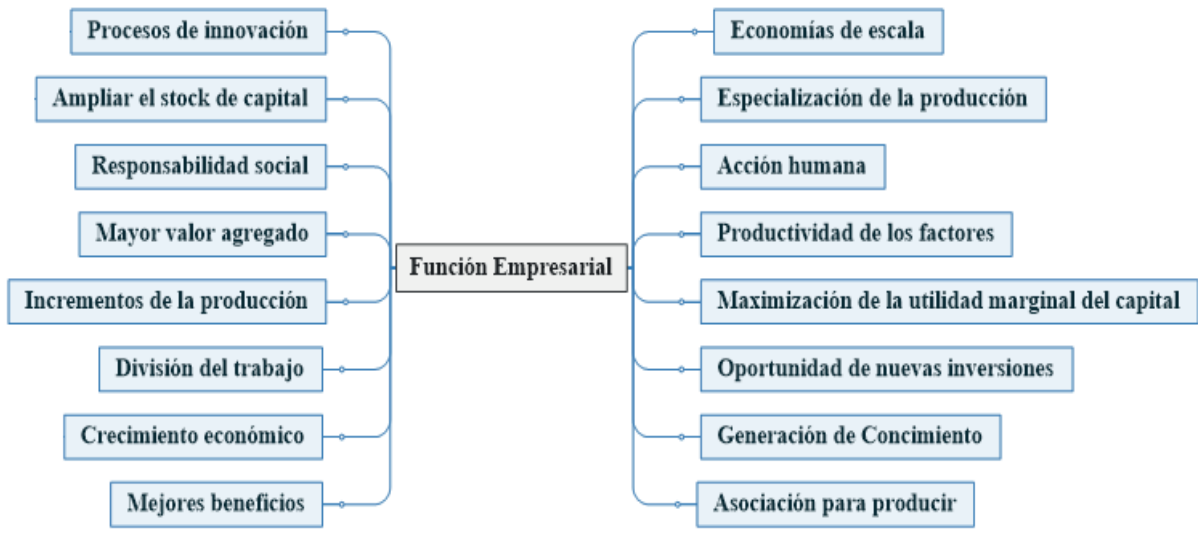

Fuente: elaboración propia

Esta concepción parte del supuesto según el cual depende de la productividad de los factores que se traduzca en un mayor nivel de valor agregado, creando oportunidades de realizar nuevas inversiones. Para generar más inversiones, es necesaria la acción humana para impulsar la libertad de asociación con la finalidad de

generar incrementos de la producción y mayores beneficios para el empresario. La consecuencia para la sociedad, es un crecimiento económico mediante los principios de la división del trabajo y la especialización de la producción (generación de conocimiento), todo ello en aras de maximizar la productividad marginal del capital y ampliar el stock de

5 Es equivalente al valor de aquellos bienes y servicios cuyo fin es su empleo en la producción de productos de nueva creación, es decir el valor que se otorga a la utilización de los denominados inputs de un proceso productivo. 
capital en un escenario de economías de escala. Ese crecimiento y productividad es para generar principalmente bienes transables de calidad mundial a un mejor precio, en un marco de responsabilidad social Huerta de Soto (2015).

Así, una característica de la función empresarial consiste en descubrir y apreciar las oportunidades que se presente en el entorno, actuando en consecuencia para lograr una ganancia o beneficio (Huerta de Soto, 2015). Ahora bien, para alcanzar dichos propósitos se requiere comprender de qué manera el entorno competitivo empresarial, modifica la información o conocimiento existente sobre el ejercicio de determinada actividad productiva. Lo anterior supone, asimilar los nuevos fines y medios que supone la modificación o actualización del empresario, lo cual a su vez le permitirá descubrir nueva información relevante (Huerta de Soto, 2015).

El conocimiento puede ser de carácter práctico, siendo adquiriendo por el individuo a través de la práctica, es decir de la propia acción humana ejercida en sus correspondientes contextos, (Huerta de Soto, 2015). Mientras el conocimiento científico, son el conjunto de saberes comprobables, obtenidos mediante el cumplimiento de los rigurosos pasos que contempla el método científico.

Ahora bien, el conocimiento práctico que existe en una organización puede ser privativo y disperso (Huerta de Soto, 2015). Es privativo, porque cada miembro de la misma posee tan solo una parte del conocimiento existente dentro de la empresa. Al mismo tiempo, la información que dicho individuo maneja, sólo él la conoce e interpreta en forma consciente. Por tanto, según (Huerta de
Soto, 2015), cada individuo que actúa y ejerce la función empresarial, lo hace estrictamente personal e irrepetible, puesto que parte de intentar alcanzar unos fines u objetivos, según una visión y conocimiento del mundo. Por ello, el conocimiento relevante para la acción humana es un conocimiento de tipo básicamente práctico y estrictamente privativo, pero que se encuentra disperso en cada uno de los individuos que componen la organización y la humanidad.

Por ello, Huerta de Soto (2015) al tratar de articular las posturas de estos cuatro autores, señala que existen dos tipos de conocimiento, indistintamente de la postura que se asuma, y las relaciones entre ellos son complejas y han sido poco estudiadas. Por consiguiente, todo conocimiento científico (tipo B) tiene una base tácita no articulable (tipo A); donde los avances científicos y técnicos (tipo B) se materializan en nuevos conocimientos prácticos (tipo A). La economía, por su parte, sería un conocimiento (tipo B) sobre los procesos de creación y transmisión del conocimiento práctico (tipo A).

\section{Conclusiones}

Luego de hacer un análisis del contexto de las pequeñas y medianas empresas en la provincia de El Oro y su relación con la composición de la actividad productiva, urge la necesidad de aprovechar las potencialidades existentes en sectores económicos como la agricultura, ganadería, silvicultura y pesca, explotación de minas y canteras, así como de manufacturas. Esas potencialidades deben ser desarrolladas por una serie de iniciativas tales como: 1) mediante de procesos de innovación empresarial 
Urdaneta Montiel, Armando José; Borgucci Garcia, Emmanuel Vitorio; González

Ordóñez, Andreina Inés; Luciani Toro, Laura Rosa

Función empresarial y la concentración de las pymes en la Provincia de el Oro, Ecuador

a partir del conocimiento existente en las organizaciones; 2) la participación de la academia: escuela, institutos de tecnología, universidades nacionales y/o internacionales; 3) convenios de cooperación a escala regional y a escala internacional. Ahora bien, el desarrollo de estas nuevas actividades 0 el reforzamiento de las existentes deben tener como resultado la generación de bienes transables, generación de tecnología y la búsqueda de nuevos mercados independientemente de su grado de acceso. Todo esto contribuirá a la promoción de mayores niveles de crecimiento económico, elevando la productividad en el empleo de los factores productivos.

Un aspecto adicional crucial para que se logre la diversificación económica por medio de la producción de bienes transables y posicionamiento en el mercado mundial, es que el sector productivo en la Provincia de El Oro se replantee su concepto, implícito o tácito, de función empresarial. Esta nueva concepción de función empresarial deberá conducir a desconcentrar el número de PYMES existentes en el sector comercio y servicios, lo cual, en lugar de generar una expansión del mercado, contribuye a: 1) una división del mercado; 2) limita los niveles de productividad por su bajo nivel tecnológico; y 3) por lo antes expuesto, su contribución a la sociedad a través del ejercicio de su actividad empresarial se ve también restringida.

Por lo cual se requiere de un cambio en la matriz productiva, trasladando buena parte factores de los factores productivos de un sector de la economía ya consolidado, hacia otros sectores menos desarrollados económicamente e industrialmente, pero con altas potencialidades. No obstante, se requiere desde el Estado crear los incentivos fiscales para tal fin, y desde el sector financiero las condiciones de financiamiento y las flexibilizaciones créditos.

\section{Referencias bibliográficas}

Arguello, L. B. (2018). Caracterización de la microempresa del sector urbano de la ciudad de Quevedo, Ecuador. Revista Nicolaita de Estudios Económicos, XIII (1), 7-27. https://bit. ly/3w4LTfV

Banco Central del Ecuador (2018). https://contenido.bce.fin.ec/ documentos/Estadisticas/ SectorReal/CuentasProvinciales/ Indicep.htm

Bada, L., Rivas, L., y Littlewood, H. (2017). Modelo de asociatividad en la cadena productiva en las Mipymes agroindustriales. Revista de Contaduría y Administración, 62, 100-1117.

Bernal, C. (2006). Metodología de la Investigación. Pearson educación, p.305

Borgucci, E. (2013). Introducción al análisis gerencial de Estados Financiero. Ediciones del Vicerrectorado Académico de la Universidad del Zulia, p. 160.

Cantillon, R. (2002[1959]). Essai sur la nature du commerce in Général. Essay on the Nature of Trade in General. Liberty Fund, Inc., p. 215.

Cobb, C. W., y Douglas, P. H. (1928). A Theory of Production. American Economic Review, 18(1), Papers and Proceedings of the Fortieth Annual Meeting of the American Economic Association (Mar., 1928), pp. 139-165 (27 pages) Published By: American Economic Association. 
Delgado, D. D. y Chávez, G. P. (2018). Las PYMES en el Ecuador y sus fuentes de financiamiento. Revista Observatorio de la Economía Latinoamericana, (abril 2018). https:/l www.eumed.net/rev/oel/2018/04/ pymes-ecuador-financiamiento.html

Domínguez, R., y Caria, S. (2016). Ecuador en la trampa de la renta media. Revista Problemas del Desarrollo, 187(47), 89-112.

Edgeworth, Francis Ysidro. (2000[1881]). Psicología matemática. Estudio preliminar: Manuel Jesús González. Traducción: Jordi Pascual. Madrid: Ediciones pirámide (Grupo Anaya, S. A.). Título original en lengua inglesa: "Mathematical Psychics. An Essay on the Application of Mathematics to Moral Sciences", p. 190.

Gomero, N. A. (2015). Concentración de las MYPES y su impacto en el crecimiento económico. Revista QUIPUKAMAYOC, 23(43), 29-39. https://revistasinvestigacion.unmsm. edu.pe/index.php/quipu/article/ view/11597

Gómez, H. J. y Borda, S. (2018). Diagnóstico de micro, pequeñas y medianas empresas, políticas $e$ instituciones de fomento en Colombia. En: MIPYMES en América Latina. Un frágil desempeño $y$ nuevos desafíos para las políticas de fomento. Coordinadores: Marco Dini y Giovanni Stumpo. CEPAL. pp. 325-383. Recuperado en línea: https://www.cepal.org/es/ publicaciones/44148-mipymesamerica-latina-un-fragil-desempenonuevos-desafios-politicas-fomento

Huerta de Soto, J. (2015). Socialismo, cálculo económico y función empresarial. 5ta. ed. Unión Editorial, p. 446

Ibujés, J. M. y Benavides, M. (2018). Contribución de la tecnología a la productividad de las pymes de la industria textil en Ecuador. Revista Cuadernos de Economía, 41, 140150.

Instituto Nacional de Estadísticas y Censos, INEC, (2017). Directorio de empresas. https:// www.ecuadorencifras.gob.ecl directoriodeempresas/

Jiménez, B. S., y Rodríguez, P. C. (2017). La inclusión de las PyMEs en la Cadena de valor de la Industria Automotriz en México en el marco del Tratado Trans-Pacífico (TTP). Revista Economía Informa, (403), 46-66.

Knight, F. (1964[1921]). Risk, Uncertainty, and Profit. New York: Augustus M. Kelley, Bookseller. Reprints of Economic Classics. https://mises. org/books/risk uncertaity_profit Knight.pdf

Kumar, R. (2011). Research Methodology a step-by-step guide for beginners. This Third edition published 2011, p.360

Marshall, A. (1963[1890]). Principios de Economía. Un tratado de introducción. Traducción directa de la 8va edición inglesa de Emilio de Figueroa. Madrid: Aguilar, S. A. de Ediciones. Título original en lengua inglesa: "Principles of Economics" (MacMillan and Co., Ltd., de Londres), p. 733.

Mill, J. S. (1985[1848]). Principios de Economía Política. Con algunas de sus aplicaciones a la filosofía social. Segunda reimpresión. Edición e introducción de Sir W. j. Ashley. Traducción de Teodoro Ortís, p. 896.

Marczyk, G., DeMatteo, D., \& Festinger, D. (2005). Essentials of Research Design and Methodology. Founding Editors, Alan S. Kaufman and Nadeen L. Kaufman. p. 290. 
Urdaneta Montiel, Armando José; Borgucci Garcia, Emmanuel Vitorio; González

Ordóñez, Andreina Inés; Luciani Toro, Laura Rosa

Función empresarial y la concentración de las pymes en la Provincia de el Oro,

Ecuador

Olea-Miranda, J., Contreras, O. F. y Barcelo-Valenzuela, M. (2016). Las capacidades de absorción del conocimiento como ventajas competitivas para la inserción de pymes en cadenas globales de valor. Revista Estudios Gerenciales, 32, 127-136.

Ortiz, A. (2015). Epistemología y ciencias humanas Educación Modelos epistémicos y paradigmas. Ediciones de la U, 2015, p.129.

Mises, L. (1982[1912]). The Theory of Money and Credit. Indianapolis, IN: Liberty Fund, Inc. Título original en Alemán: "Theorie des Geldes und der Umlaufsmittel", p. 514.

Mises, L. (1996[1949]). Human Action: A Treatise on Economics. Fourth revised edition. Foreword by Bettina Bien Greaves. New York: Irvingtonon-Hudson: The Foundation for Economic Education, p. 920.

Peña, M. J. y Vega, N. E. (2017). Estructura de las PYMES en la economía ecuatoriana. Revista Sur Academia, 1(8), 30-34. https:// revistas.unl.edu.ec/index.php/ suracademia/article/view/519

Ricardo, D. (1973[1950]).Principios de Economía Política y Tributación. Segunda reimpresión. Traducción de Juan Broc. B, Nelly Wolff y Julio Estrada. Título original en lengua inglesa: "The Works and Correspondence of David Ricardo (Edición de Piero Sraffa), Vol. I: On the Principles of Political Economy and Taxation". Cambridge University Press.p.332.

Romero, F., Melgarejo, A., y Vera-Colina, M. A. (2015). Fracaso empresarial de las pequeñas y medianas empresas (PYMES) en Colombia. Revista Suma de Negocios, 6 (13), 2941. https://www.researchgate.net/ publication/283194644 Fracaso empresarial de las pequenas y medianas empresas pymes en Colombia

Ron, R. E. y Sacoto, V. A. (2017). Las PYMES ecuatorianas: su impacto en el empleo como contribución del PIB PYMES al PIB total. Revista Espacios, 38 (53), 15. https://www. revistaespacios.com/a17v38n53/ a17v38n53p15.pdf

Say, J. B. (2001[1841]). Tratado de Economía Política. Primera edición en español. México, D. F.: Fondo de Cultura Económica. Título original en lengua francesa: "Traité d'Économie Politique”, p. 498.

Schumpeter, J. A. (1994[1954]). Historia del Análisis económico. Barcelona: Editorial Ariel, S.A. título original en lengua inglesa: History of Economics Analysis, p. 1377.

Schumpeter, J. (1976[1912]). Teoría del desenvolvimiento económico: una investigación sobre ganancias, capital, crédito, interés y ciclo económico. Cuarta reimpresión. Fondo de Cultura Económica de México. México. D.F., p. 254.

Smith, A. (1982[1776]). Investigación sobre la Naturaleza y Causas de la Riqueza de las Naciones. Tercera reimpresión. Edición de Edwin Cannan. Traducción de Gabriel Franco. Fondo de Cultura Económica. Título original en lengua inglesa: "The Wealth of Nations", p. 917.

Stezano, F. (2018). Diagnóstico de micro, pequeñas y medianas empresas, políticas e instituciones de fomento en México. En: MIPYMES en América Latina. Un frágil desempeño y nuevos desafíos para las políticas de fomento. Coordinadores: Marco Dini y Giovanni Stumpo. CEPAL. 325-383. https://www.cepal.org/ es/publicaciones/44148-mipymes- 
pp. 776-801

Revista Venezolana de Gerencia, Año 26 No. 95, 2021

america-latina-un-fragil-desempenonuevos-desafios-politicas-fomento

Trincado, A. E. (2009). Teorías del valor y la función empresarial. Revista Investigaciones de Historias Económicas, 5(14).

Turgot, Anne-Robert J. (1998). Cuadro filosófico de los progresos sucesivos del espíritu humano y otros textos. Selección y traducción de Francisco
González Aramburu. Fondo de Cultura Económica, p. 248.

Yance, C., Solís, I., Burgos, I. y Hermida, L. (2017). La importancia de las PYMES en el Ecuador. Revista Observatorio de la Economía Latinoamericana, (junio 2017). https://www.eumed.net/cursecon/ ecolat/ec/2017/pymes-ecuador.html 